\title{
Adverse Event Coding System
}

National Cancer Institute

\section{Source}

National Cancer Institute. Adverse Event Coding System. NCI Thesaurus. Code C93502.

The coding system used for recording adverse events for a study. 